\title{
Major hepatectomy for perihilar cholangiocarcinoma in elderly patients: is it reasonable?
}

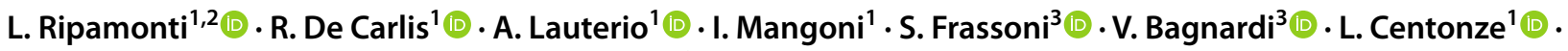

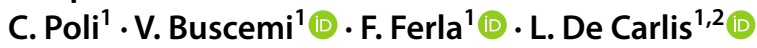

Received: 7 March 2021 / Accepted: 8 June 2021 / Published online: 17 June 2021

(c) The Author(s) 2021

\begin{abstract}
Introduction We sought to evaluate the effect of age on postoperative outcomes among patients undergoing major liver surgery for perihilar cholangiocarcinoma (PHCC).

Methods 77 patients were included. Patients were categorized into two groups: the "<70-year-olds" group $(n=54)$ and the " $\geq 70$-year-olds" group $(n=23)$.

Results Median LOS was 19 both for $<70$-year-old group and $\geq 70$-year-old group $(P=0.72)$. No differences in terms of severe complication were detected (44.4\% Clavien-Dindo 3-4-5 in $<70$-year-old group vs $47.8 \%$ in $\geq 70$-year-old group, $P=0.60)$. Within 90 postoperative days, 11 patients died, 6 in $<70$-year-old group $(11.3 \%)$ and 5 in $\geq 70$-year-old group (21.7\%), $P=0.29$. The median follow-up was 20 months. The death rate was $72.2 \%$ and $78.3 \%$ among patients $<70$ years old and $\geq 70$ years old. The OS at 2 and 5 years was significantly higher among the $<70$ years old $(57.0 \%$ and $27.7 \%)$ compared to the $\geq 70$ years old $(27.1 \%$ and $13.6 \%), P=0.043$. Adjusting for hypertension and Charlson comorbidity index in a multivariate analysis, the HR for age was 1.93 (95\% CI 0.84-4.44), $P=0.12$. Relapse occurred in 43 (81.1\%) patients in the $<70$-year-old group and in $19(82.6 \%)$ patients in the $\geq 70$-year-old group. DFS at 12, 24, and 36 months was, respectively, 59.6, 34.2, and 23.2 for the $<70$-year-old group and 32.5, 20.3, and 13.5 for the $\geq 70$-year-old group $(P=0.26)$. Adjusting for hypertension and Charlson comorbidity index in a Cox model, the HR for age was 1.52 (95\% CI 0.67-3.46), with $P=0.32$.

Conclusions $\geq 70$-year-old patients with PHCC can still be eligible for major liver resection with acceptable complication rates and should not be precluded a priori from a radical treatment.
\end{abstract}

Keywords Perihilar $\cdot$ Cholangiocarcinoma $\cdot$ Elderly $\cdot$ Hepatectomy $\cdot$ Liver $\cdot$ Klatskin

\section{Introduction}

Perihilar cholangiocarcinoma (PHCC), or Klatskin tumor, is an advanced tumor at or near the confluence of the right and left hepatic duct. With approximately 5,000 new cases diagnosed annually in the United States, PHCC represents less than $2 \%$ of all malignancies, yet accounts for over $60 \%$ of all cholangiocarcinomas. Surgical resection is the only

L. Ripamonti

1.ripamonti10@campus.unimib.it

1 Department of General Surgery and Transplantation, ASST Grande Ospedale Metropolitano Niguarda, Milan, Italy

2 Department of Medicine and Surgery, University of Milano-Bicocca, Milan, Italy

3 Department of Statistics and Quantitative Methods, University of Milan-Bicocca, Milan, Italy way to cure this disease, as chemotherapy with or without radiation is less effective [1-3]. Due to the difficulty, risks, and complexity of resection, hepatectomy has rarely been offered to elderly patients with PHCC. Older patients often have a higher incidence of medical comorbidities, worse performance status, as well as decreased functional reserve that may place them at particular risk for worse postoperative outcomes [4]. The incidence of Klatskin tumors increases with age, with a peak between 60 and 80 years [5]. Improvements in living conditions and progress in medical and surgical management have resulted in aging of the population. According to the Italian National Institute for Statistics (Istituto Nazionale di Statistica, ISTAT), people aged 70 and older in Italy in 2017 represent 17\% of the inhabitants with a life expectancy of 83 years (instead $13 \%$ and 80 years in 2003) [6, 7]. In consideration of this improvement in life expectancy, it is of great importance 
to treat elderly people properly by attempting to offer them radical surgery in accordance with their comorbidities and functional status. Different studies treating different liver tumors have proven the safety and feasibility of liver resection for elderly patients with an acceptably low complication rate and adequate oncologic outcomes [8-10]. In this study, we sought to evaluate the effect of age on postoperative outcomes among patients undergoing liver surgery for PHCC. In particular, we aimed to compare perioperative outcomes including postoperative complications, 90-day mortality, and length of stay (LOS), as well as oncological outcomes like disease-free survival (DFS) and overall survival (OS) between elderly patients ( $\geq 70$ years old) and younger $(<70$ years old $)$ undergoing liver major resection for PHCC.

\section{Methods}

The study evaluated consecutive 122 adult ( $\geq 18$ years) patients diagnosed with PHCC and recruited between January 2009 and December 2019 at our Institution. The pathology of PHCC was diagnosed according to the World Health Organization and AJCC criteria $[11,12]$. Intrahepatic and distal cholangiocarcinoma, gallbladder carcinoma, hepatocellular carcinoma, and all secondary liver malignancies were excluded. Data were collected retrospectively and anonymized prior to the analysis. Ten patients were excluded due to missing data and 29 patients were excluded, because only surgical exploration without resection or palliative surgery was performed and 6 patients dropped out of the follow-up. Overall, 77 patients resected for PHCC were included in the study. Patients were categorized into two groups according to the different age: the " $<70$-year-olds" group (age $<70, n=54$ ) and the " $\geq 70$-year-olds" group (age $\geq 70, n=23$ ) (Fig. 1). For each group, baseline characteristics, post-operative results, and survival were evaluated.

All patients signed informed consent that data and followup will be collected anonymously and is potentially used for scientific analysis. This study complied with the standards of the Declaration of Helsinki and current ethical guidelines, and no ethical approval was necessary owing to the retrospective, observational, and anonymous nature of this study.

\section{Preoperative management and follow-up}

Preoperative imaging examinations, including contrastenhanced computer tomography (CT) and/or magnetic resonance imaging (MRI), were performed routinely and reviewed for this study by an expert radiologist. Serum biochemical was used to assess liver function. Considering the potential risk of postoperative complications and hilar

Fig. 1 Patient selection

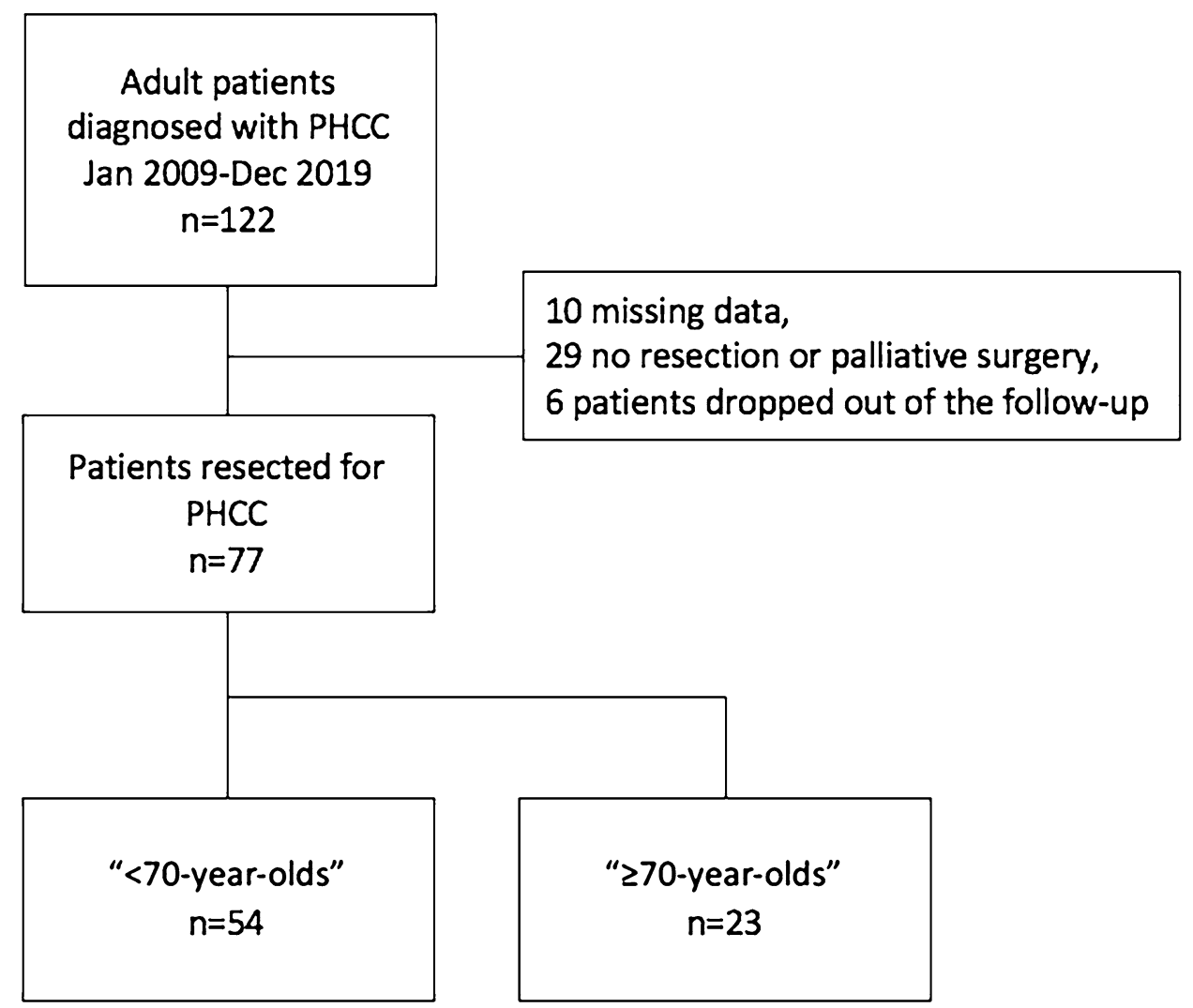


sclerosis associated with preoperative biliary drainage, we considered drainage for patients who presented with preoperative cholangitis, experienced a significant delay in surgery for various reasons, or for whom we planned an extensive resection (e.g., trisectionectomy). Otherwise, we tolerated a moderate degree of jaundice and duct dilatation, especially in the case of left hepatectomies. We usually drain only the future liver remnant with percutaneous or, less frequently, endoscopic biliary drainage. Preoperative portal vein embolization (PVE) in our series was considered if a trisectionectomy was planned (with an approximately cut-off of future liver remnant (FLR) of $<25 \%$ ).

\section{Surgery}

Every hepatectomy had a laparotomic approach. The type of hepatectomy was determined by the location of the primary tumor basing on the Bismuth-Corlette classification. Caudate lobe resection was performed in every case. Lymphadenectomy was always a routine part of the resection procedure. When distant lymph-node metastasis (M1 disease) was found at laparotomy, resection was abandoned in principle.

The parenchymal transection was performed using Cavitron Ultrasonic Surgical Aspirator (CUSA), under both hepatic artery and portal vein clamping for 15 or $20 \mathrm{~min}$ (according to surgeon's preference) at 5-min intervals. Bilioenteric continuity was reestablished by Roux-en-Y cholangiojejunostomy.

\section{Pathology}

Clear resection margin (R0) was defined as the distance between the nontumorous tissue and cancer cell $>1 \mathrm{~mm}$. R1 resection referred to resection margin touching inked tumor on the hepatic section line. The resection margins of the bile duct were investigated by frozen section. $\mathrm{R} 2$ resection means gross residual disease on the hepatic section line.

\section{Outcomes}

The primary outcomes were to evaluate the differences between age classes in terms of surgical outcomes (rate of complications, LOS, and 90-day mortality). Post-operative complications were recorded and considered as any deviation from the normal recovery requiring pharmacological or interventional treatments. The severity of complication was assessed by the Clavien-Dindo (CD) classification [13] and comprehensive complication index (CCI) [14].

The secondary outcomes were overall survival and disease-free survival among the two groups.

\section{Statistical analysis}

Continuous data are reported as median and ranges. Categorical data are reported as counts and percentages.

Wilcoxon's signed-rank test for continuous variables, Fisher's exact test for binary variables, and Cochran-Armitage's trend test for ordinal variables were used to compare the distribution of the evaluated characteristics between patients under and over 70 years.

To evaluate the effect of age on postoperative outcomes, different univariate models were performed: linear regression model for length of hospital stay and CCI, ordinal logistic model for Clavien-Dindo (3 ordinal levels: 0, 1-2, 3-4-5), and binary logistic model for 90-day mortality. The overall survival (OS) and disease-free survival (DFS) functions were estimated using the Kaplan-Meier method. The log-rank test was used to assess differences between the two age groups.

Multivariate models (linear, ordinal logistic, binary logistic, and cox proportional hazard) were then performed, to adjust the effect of age at surgery for the baseline characteristics that significantly differed between the two age groups $(P<0.05)$ at univariate analysis.

All analyses were performed with the statistical software SAS 9.4 (SAS Institute, Cary, NC).

\section{Results}

Between January 2009 and December 2019, overall 77 patients resected for PHCC were included in the study. As shown in Table 1 at the baseline, the groups were significantly different in terms of hypertension, ASA score, and Performance Status. Patients who underwent percutaneous or endoscopic biliary drainage were $25(46.3 \%)$ in the $<70$-year-old group and $11(47,8 \%)$ in the $\geq 70$-year-old group respectively $(P=1.00)$. No significant differences were found considering surgery and preoperative management (Table 2). In the < 70-year-old group, 18 (33.3\%) patients had right hepatectomy, 3 (5.6\%) had right trisectionectomy, 32 (59.3\%) had left hepatectomy, and 1 (1.9\%) had left trisectionectomy. In the $\geq 70$-year-old group, 10 (43.5\%) patients had right hepatectomy, 1 (4.3\%) had right trisectionectomy, 15 (52.2\%) had left hepatectomy, and none had left trisectionectomy $(P=0.88)$. No differences between the two groups also considering Bismuth-Corlette classification, pathology and TNM staging (Table 3). Overall R0 resection was obtained in $77.1 \%$ of cases, $74 \%$ in the $<70$-year-old group and $85 \%$ in the $\geq 70$-year-old group. Concerning postoperative short-term outcomes (Table 4) there are no differences between the two groups. Median LOS was 19 (5-99) for $<70$-year-old group and 19 (8-90) for $\geq 70$-year-old group $(P=0.72)$. The total rate of 
Table 1 Baseline characteristics

\begin{tabular}{|c|c|c|c|c|c|}
\hline \multirow[t]{2}{*}{ Variable } & \multirow[t]{2}{*}{ Level } & \multirow[t]{2}{*}{ Overall $(N=77)$} & \multicolumn{2}{|l|}{ Age at surgery } & \multirow[t]{2}{*}{$P$ value } \\
\hline & & & $<70,(N=54)$ & $\geq 70,(N=23)$ & \\
\hline Age, median (min-max) & & $66(28-85)$ & $61(28-69)$ & $73(70-85)$ & - \\
\hline \multirow[t]{3}{*}{ Diabetes mellitus, $N(\%)$} & No & $70(94.6)$ & $50(96.2)$ & $20(90.9)$ & 0.58 \\
\hline & Yes & $4(5.4)$ & $2(3.8)$ & $2(9.1)$ & \\
\hline & Missing & 3 & 2 & 1 & \\
\hline \multirow[t]{3}{*}{ Hypertension, $N(\%)$} & No & $48(64.9)$ & $42(80.8)$ & $6(27.3)$ & $<0.001$ \\
\hline & Yes & $26(35.1)$ & $10(19.2)$ & $16(72.7)$ & \\
\hline & Missing & 3 & 2 & 1 & \\
\hline \multirow[t]{3}{*}{ Cardiovascular comorbidity, $N(\%)$} & No & $69(93.2)$ & $49(94.2)$ & $20(90.9)$ & 0.63 \\
\hline & Yes & $5(6.8)$ & $3(5.8)$ & $2(9.1)$ & \\
\hline & Missing & 3 & 2 & 1 & \\
\hline \multirow[t]{3}{*}{ Vascular comorbidity, $N(\%)$} & No & $70(94.6)$ & $50(96.2)$ & $20(90.9)$ & 0.58 \\
\hline & Yes & $4(5.4)$ & $2(3.8)$ & $2(9.1)$ & \\
\hline & Missing & 3 & 2 & 1 & \\
\hline \multirow[t]{3}{*}{ Liver disease, $N(\%)$} & No & $70(94.6)$ & $49(94.2)$ & $21(95.5)$ & 1.00 \\
\hline & Yes & $4(5.4)$ & $3(5.8)$ & $1(4.5)$ & \\
\hline & Missing & 3 & 2 & 1 & \\
\hline \multirow[t]{3}{*}{ Respiratory disease, $N(\%)$} & No & $65(87.8)$ & $47(90.4)$ & $18(81.8)$ & 0.44 \\
\hline & Yes & $9(12.2)$ & $5(9.6)$ & $4(18.2)$ & \\
\hline & Missing & 3 & 2 & 1 & \\
\hline \multirow[t]{3}{*}{ Renal insufficiency, $N(\%)$} & No & $71(95.9)$ & $51(98.1)$ & $20(90.9)$ & 0.21 \\
\hline & Yes & $3(4.1)$ & $1(1.9)$ & $2(9.1)$ & \\
\hline & Missing & 3 & 2 & 1 & \\
\hline \multirow[t]{3}{*}{ Previous tumor, $N(\%)$} & No & $71(95.9)$ & $50(96.2)$ & $21(95.5)$ & 1.00 \\
\hline & Yes & $3(4.1)$ & $2(3.8)$ & $1(4.5)$ & \\
\hline & Missing & 3 & 2 & 1 & \\
\hline \multirow[t]{3}{*}{ Autoimmune disease, $N(\%)$} & No & $71(95.9)$ & $49(94.2)$ & $22(100.0)$ & 0.55 \\
\hline & Yes & $3(4.1)$ & $3(5.8)$ & $0(0.0)$ & \\
\hline & Missing & 3 & 2 & 1 & \\
\hline \multirow[t]{5}{*}{ Performance status (ECOG), $N(\%)$} & 0 & $45(60.8)$ & $39(75.0)$ & $6(27.3)$ & 0.004 \\
\hline & 1 & $24(32.4)$ & $9(17.3)$ & $15(68.2)$ & \\
\hline & 2 & $4(5.4)$ & $4(7.7)$ & $0(0.0)$ & \\
\hline & 3 & $1(1.4)$ & $0(0.0)$ & $1(4.5)$ & \\
\hline & Missing & 3 & 2 & 1 & \\
\hline \multirow[t]{5}{*}{ ASA, $N(\%)$} & 1 & $28(37.3)$ & $25(47.2)$ & $3(13.6)$ & 0.001 \\
\hline & 2 & $32(42.7)$ & $22(41.5)$ & $10(45.5)$ & \\
\hline & 3 & $14(18.7)$ & $6(11.3)$ & $8(36.4)$ & \\
\hline & 4 & $1(1.3)$ & $0(0.0)$ & $1(4.5)$ & \\
\hline & Missing & 2 & 1 & 1 & \\
\hline $\begin{array}{l}\text { Charlson Comorbidity Index, } \\
\text { median }(\min -\max )^{\mathrm{a}}\end{array}$ & & $4(2-8)$ & $4(2-7)$ & $5(5-8)$ & $<0.001$ \\
\hline
\end{tabular}

ECOG Eastern Cooperative Oncology Group, ASA American Society of Anesthesiologists

a 3 missing values

complications after surgery was $87.0 \%$ for $<70$-year-old group, $73.9 \% \geq 70$-year-old group. Nevertheless, no differences in terms of severe complication were detected $(44.4 \%$ Clavien-Dindo 3-4-5 in $<70$-year-old group vs $47.8 \%$ in $\geq 70$-year-old group, $P=0.60$ ). The majority of severe complications were perihepatic fluid collection treated with percutaneous drainage. A biliary fistula was diagnosed in $9(16.6 \%)$ patients in the $<70$-year-old group and in 3 (12.5\%) patients in the $\geq 70$-year-old group. Median CCI was 30.8 (30.8 in $<70$-year-old group and 29.6 in $\geq 70$-yearold group, $P=0.85)$. A total of 11 patients $(14.5 \%)$ died within 90 postoperative days, 6 in $<70$-year-old group 
Table 2 Type of surgery and preoperative management

\begin{tabular}{|c|c|c|c|c|c|}
\hline \multirow[t]{2}{*}{ Variable } & \multirow[t]{2}{*}{ Level } & \multirow[t]{2}{*}{ Overall $(N=77)$} & \multicolumn{2}{|l|}{ Age at surgery } & \multirow[t]{2}{*}{$P$ value } \\
\hline & & & $<70,(N=54)$ & $\geq 70,(N=23)$ & \\
\hline \multirow{2}{*}{$\begin{array}{l}\text { Preoperative portal vein emboli- } \\
\text { zation, } N(\%)\end{array}$} & No & $73(94.8)$ & $51(94.4)$ & $22(95.7)$ & 1.00 \\
\hline & Yes & $4(5.2)$ & $3(5.6)$ & $1(4.3)$ & \\
\hline \multirow[t]{2}{*}{ Preoperative dren, $N(\%)$} & No & $41(53.2)$ & $29(53.7)$ & $12(52.2)$ & 1.00 \\
\hline & Yes & $36(46.8)$ & $25(46.3)$ & $11(47.8)$ & \\
\hline \multirow[t]{4}{*}{ Type of surgery, $N(\%)$} & Right hemihepatectomy & $28(36.4)$ & $18(33.3)$ & $10(43.5)$ & 0.88 \\
\hline & Right trisectionectomy & $4(5.2)$ & $3(5.6)$ & $1(4.3)$ & \\
\hline & Left hemihepatectomy & $44(57.1)$ & $32(59.3)$ & $12(52.2)$ & \\
\hline & Left trisectionectomy & $1(1.3)$ & $1(1.9)$ & $0(0.0)$ & \\
\hline \multirow[t]{3}{*}{ Vascular resection, $N(\%)$} & No vascular resection & $73(94.8)$ & $51(94.4)$ & $22(95.7)$ & 0.77 \\
\hline & Portal vein resection & $2(2.6)$ & $1(1.9)$ & $1(4.3)$ & \\
\hline & Hepatic artery resection & $2(2.6)$ & $2(3.7)$ & $0(0.0)$ & \\
\hline
\end{tabular}

Table 3 Pathology

\begin{tabular}{|c|c|c|c|c|c|}
\hline \multirow[t]{2}{*}{ Variable } & \multirow[t]{2}{*}{ Level } & \multirow[t]{2}{*}{ Overall $(N=77)$} & \multicolumn{2}{|l|}{ Age at surgery } & \multirow[t]{2}{*}{$P$ value } \\
\hline & & & $<70,(N=54)$ & $\geq 70,(N=23)$ & \\
\hline \multirow[t]{4}{*}{ Grading, $N(\%)$} & G1 & $11(15.5)$ & $8(15.7)$ & $3(15.0)$ & \multirow[t]{4}{*}{0.20} \\
\hline & G2 & $46(64.8)$ & $30(58.8)$ & $16(80.0)$ & \\
\hline & G3 & 14 (19.7) & $13(25.5)$ & $1(5.0)$ & \\
\hline & Missing & 6 & 3 & 3 & \\
\hline \multirow[t]{4}{*}{ Resection margins, $N(\%)$} & R0 & $54(77.1)$ & $37(74.0)$ & $17(85.0)$ & \multirow[t]{4}{*}{0.29} \\
\hline & $\mathrm{R} 1$ & $15(21.4)$ & $12(24.0)$ & $3(15.0)$ & \\
\hline & $\mathrm{R} 2$ & $1(1.4)$ & $1(2.0)$ & $0(0.0)$ & \\
\hline & Missing & 7 & 4 & 3 & \\
\hline \multirow[t]{3}{*}{$\mathrm{T}, N(\%)$} & $\mathrm{T} 1-\mathrm{T} 2$ & $46(66.7)$ & $31(63.3)$ & $15(75.0)$ & \multirow[t]{3}{*}{0.41} \\
\hline & T3-T4 & $23(33.3)$ & $18(36.7)$ & $5(25.0)$ & \\
\hline & Missing & 8 & 5 & 3 & \\
\hline \multirow[t]{3}{*}{$\mathrm{N}, N(\%)$} & No & $43(64.2)$ & $27(57.4)$ & $16(80.0)$ & \multirow[t]{3}{*}{0.099} \\
\hline & N1 & $24(35.8)$ & $20(42.6)$ & $4(20.0)$ & \\
\hline & Missing & 10 & 7 & 3 & \\
\hline \multirow{4}{*}{$\begin{array}{l}\text { Bismuth-Corlette classifi- } \\
\text { cation, } N(\%)\end{array}$} & II & $8(10.4)$ & $7(13.0)$ & $1(4.3)$ & \multirow[t]{4}{*}{0.43} \\
\hline & IIIA & $27(35.1)$ & $16(29.6)$ & $11(47.8)$ & \\
\hline & IIIB & $38(49.4)$ & $28(51.9)$ & $10(43.5)$ & \\
\hline & IV & $4(5.2)$ & $3(5.6)$ & $1(4.3)$ & \\
\hline
\end{tabular}

(11.3\%), and 5 in $\geq 70$-year-old group (21.7\%), $P=0.29$. The median follow-up for the whole sample was 20 months (IQR 8-37). The death rate was $72.2 \%$ and $78.3 \%$ among patients $<70$ years old and $\geq 70$ years old, respectively. The median OS was 29 (95\% CI 19-37) months for the $<70$-yearold group and 15 (95\% CI 8-23) for the $\geq 70$-year-old group. The OS was significantly higher among the $<70$ years old (57.0\% and $27.7 \%$ at 2 and 5 years, respectively) compared to the $\geq 70$ years old $(27.1 \%$ and $13.6 \%$ at 2 and 5 years, respectively, $P=0.043$ ), as shown in Fig. 2. Adjusting for hypertension and Charlson comorbidity index in a multivariate Cox proportional hazard regression model, the HR for age was 1.93 (95\% CI 0.84-4.44), with $P=0.12$. Relapse occurred in $43(81.1 \%)$ patients in the $<70$-yearold group and in $19(82.6 \%)$ patients in the $\geq 70$-year-old group. DFS at 12, 24, and 36 months was, respectively, 59.6 (45.0-71.5), $34.2(21.4-47.5)$, and $23.2(12.4-35.9)$ for the $<70$-year-old group and 32.5 (14.6-51.8), 20.3 (6.0-40.4), and 13.5 (2.6-33.5) for the $\geq 70$-year-old group $(P=0.26)$, as shown in Fig. 3. Adjusting for hypertension and Charlson comorbidity index in a Cox model, the HR for age was 1.52 (95\% CI 0.67-3.46), with $P=0.32$. 
Table 4 Outcomes

\begin{tabular}{|c|c|c|c|c|c|c|}
\hline \multirow[t]{2}{*}{ Variable } & \multirow[t]{2}{*}{ Level } & \multirow[t]{2}{*}{ Overall $(N=77)$} & \multicolumn{2}{|l|}{ Age at surgery } & \multirow{2}{*}{$\begin{array}{l}P \text { value of uni- } \\
\text { variate analysis }\end{array}$} & \multirow{2}{*}{$\begin{array}{l}P \text { value of } \\
\text { adjusted } \\
\text { analysis }^{\mathrm{a}}\end{array}$} \\
\hline & & & $<70,(N=54)$ & $\geq 70,(N=23)$ & & \\
\hline Hospital stay, median $(\min -\max )^{\mathrm{b}}$ & & $19(5-99)$ & $19(5-99)$ & $19(8-90)$ & 0.92 & 0.20 \\
\hline \multirow[t]{8}{*}{ Clavien-Dindo, $N(\%)$} & 0 & $13(16.9)$ & $7(13.0)$ & $6(26.1)$ & - & - \\
\hline & 1 & $6(7.8)$ & $5(9.3)$ & $1(4.3)$ & & \\
\hline & 2 & $23(29.9)$ & $18(33.3)$ & $5(21.7)$ & & \\
\hline & $3 a$ & $15(19.5)$ & $10(18.5)$ & $5(21.7)$ & & \\
\hline & $3 b$ & $5(6.5)$ & $5(9.3)$ & $0(0.0)$ & & \\
\hline & $4 \mathrm{a}$ & $5(6.5)$ & $4(7.4)$ & $1(4.3)$ & & \\
\hline & $4 \mathrm{~b}$ & $1(1.3)$ & $1(1.9)$ & $0(0.0)$ & & \\
\hline & 5 & $9(11.7)$ & $4(7.4)$ & $5(21.7)$ & & \\
\hline \multirow[t]{3}{*}{ Clavien-Dindo, $N(\%)$} & 0 & $13(16.9)$ & $7(13.0)$ & $6(26.1)$ & 0.73 & 0.40 \\
\hline & $1-2$ & $29(37.7)$ & $23(42.6)$ & $6(26.1)$ & & \\
\hline & $3-4-5$ & $35(45.5)$ & $24(44.4)$ & $11(47.8)$ & & \\
\hline CCI, median (min-max) & & $30.8(0-100)$ & $30.8(0-100)$ & $29.6(0-100)$ & 0.54 & 0.38 \\
\hline \multirow[t]{3}{*}{ Death at 90 days post-op, $N(\%)$} & No & $65(85.5)$ & $47(88.7)$ & $18(78.3)$ & 0.24 & 0.59 \\
\hline & Yes & $11(14.5)$ & $6(11.3)$ & $5(21.7)$ & & \\
\hline & Missing & 1 & 1 & 0 & & \\
\hline
\end{tabular}

CCI Comprehensive Complication Index

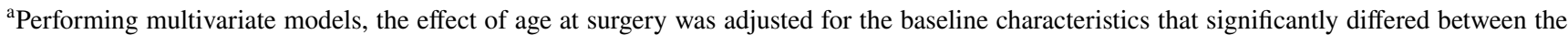
two age groups $(P<0.05)$ at univariate analysis: hypertension and Charlson Comorbidity Index. Also PS ECOG and ASA were associated with age, but they were highly correlated with Charlson, so we excluded them from multivariate models to avoid multicollinearity)

b 3 missing values

\section{Discussion}

The feasibility of major liver surgery in elderly patients is discussed intensively. Social demographic trends to develop an older society. Given the increasing aged surgical population, it is not surprising that the number of elderly patients undergoing hepatic resection for treatment of liver cancer is progressively increasing. Tufo and colleagues [15] showed that the number of patients who underwent liver resection older than 70 years raised from $6 \%$ of 1990 to $>25 \%$ in 2007 . Although several studies have examined the feasibility of hepatic resection for colorectal liver metastasis (CRLM), intrahepatic cholangiocarcinoma (ICC), and hepatocarcinoma (HCC) among elderly patients [8-10, 15-19], the results were disparate. Only one previous study showed that resection of PHCC under careful patient selection can be performed with low mortality irrespective of age and offers a better chance of long-term survival even in octogenarians [20]. Caution, however, is needed for interpretation of data, because nearly all previous studies involved patients who underwent simple hepatectomy without bilioenteric anastomosis. In this study, we evaluate the effect of age on postoperative outcomes among patients undergoing liver surgery for PHCC. In particular, we demonstrated that there were no differences in perioperative outcomes including postoperative complications, 90-day mortality, and length of stay (LOS) between patients younger ( $<70$ years old) and elderly ( $\geq 70$ years old). Usually, elderly patients may have more comorbidities and a long hospital stay can increase complications rate and costs: in light of this, a crucial role is assigned to patients' preoperative assessment. Cost control is nowadays a very important aspect of many health systems, which raises the question what proportion of health care resources should be allocated to the older population [19]. In the current aging society, surgeons are increasingly treating more elderly patients with cancer. Elderly patients with PHCC should not be precluded from appropriate resection of PHCC solely due to age. Although there are several scoring systems to predict postoperative mortality and morbidity, there is no evidence to indicate whether these systems are applicable for PHCC [20]. Frailty is associated with a worse survival outcome in patients with various malignancies. However, it is not a risk factor for survival in biliary tract cancer with good ECOG performance score [21]. About oncological outcomes, no difference was found for the disease-free survival (DFS), while a little difference was found between the two groups for the overall survival (OS). This finding is not unexpected, since the likelihood of death for any reason inherently increases with age progression. In the literature, Akashi and colleagues [20] reached same 


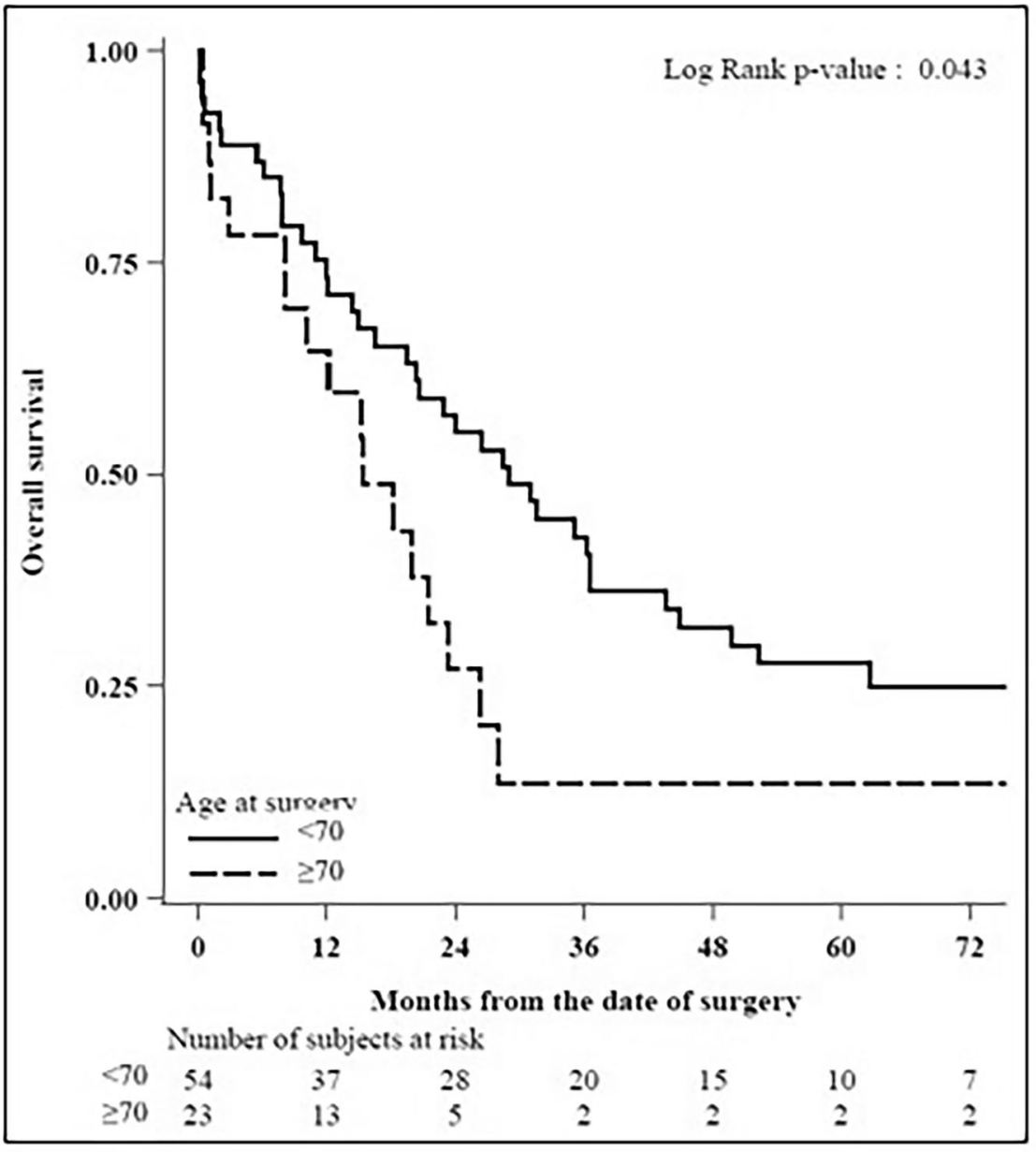

\begin{tabular}{|c|c|c|c|c|c|c|}
\hline Age at surgery & Deaths & $\begin{array}{c}\text { Median OS } \\
(95 \% \mathrm{CI})\end{array}$ & $\begin{array}{l}12-\mathrm{mo} \mathrm{OS} \\
(95 \% \mathrm{CI})\end{array}$ & $\begin{array}{l}24-\mathrm{mo} \mathrm{OS} \\
(95 \% \mathrm{CI})\end{array}$ & $\begin{array}{l}36-\mathrm{mo} \mathrm{OS} \\
(95 \% \mathrm{CI})\end{array}$ & $\begin{array}{l}60-\mathrm{mo} \text { OS } \\
(95 \% \mathrm{CI})\end{array}$ \\
\hline 570 & $39(72.2 \%)$ & $29(19.37)$ & $73.3(59.0-83.2)$ & $57.0(42.3 \cdot 69.3)$ & $42.6(28.8-55.8)$ & $27.7(16.0 .40 .7)$ \\
\hline$\geq 70$ & $18(78.3 \%)$ & $15(8.23)$ & $64.6(41.4-80.5)$ & $27.1(10.1-47.5)$ & $13.6(2.5 \cdot 33.8)$ & $13.6(2.5 \cdot 33.8)$ \\
\hline
\end{tabular}

Fig. 2 Overall survival

results about perihilar cholangiocarcinoma but evaluating an older population. That confirms that surgery does not impact in life expectancy of elderly patients. For Vitale et al. [17], both OS and DFS were comparable among elderly and non-elderly patients. In contrast, tumor characteristics were more predictive of worse survival. The current study has several limitations. This is a retrospective monocentric analysis, and the study cohort is inevitably small. Therefore, no definitive conclusions can be drawn due to the limited numbers in the two groups considered. In this context, a multicentric study would raise the number of included patients and the power of statistical testing.
Moreover, the scarcity of data in the literature makes it difficult to compare our results.

\section{Conclusions}

In the current aging society, surgeons are increasingly treating more elderly patients with cancer. Our results suggest that, despite an inferior OS, $\geq 70$-year-old patients with PHCC can still be eligible for major liver resection with acceptable complication rates and perioperative results, and should not be precluded a priori from a radical 


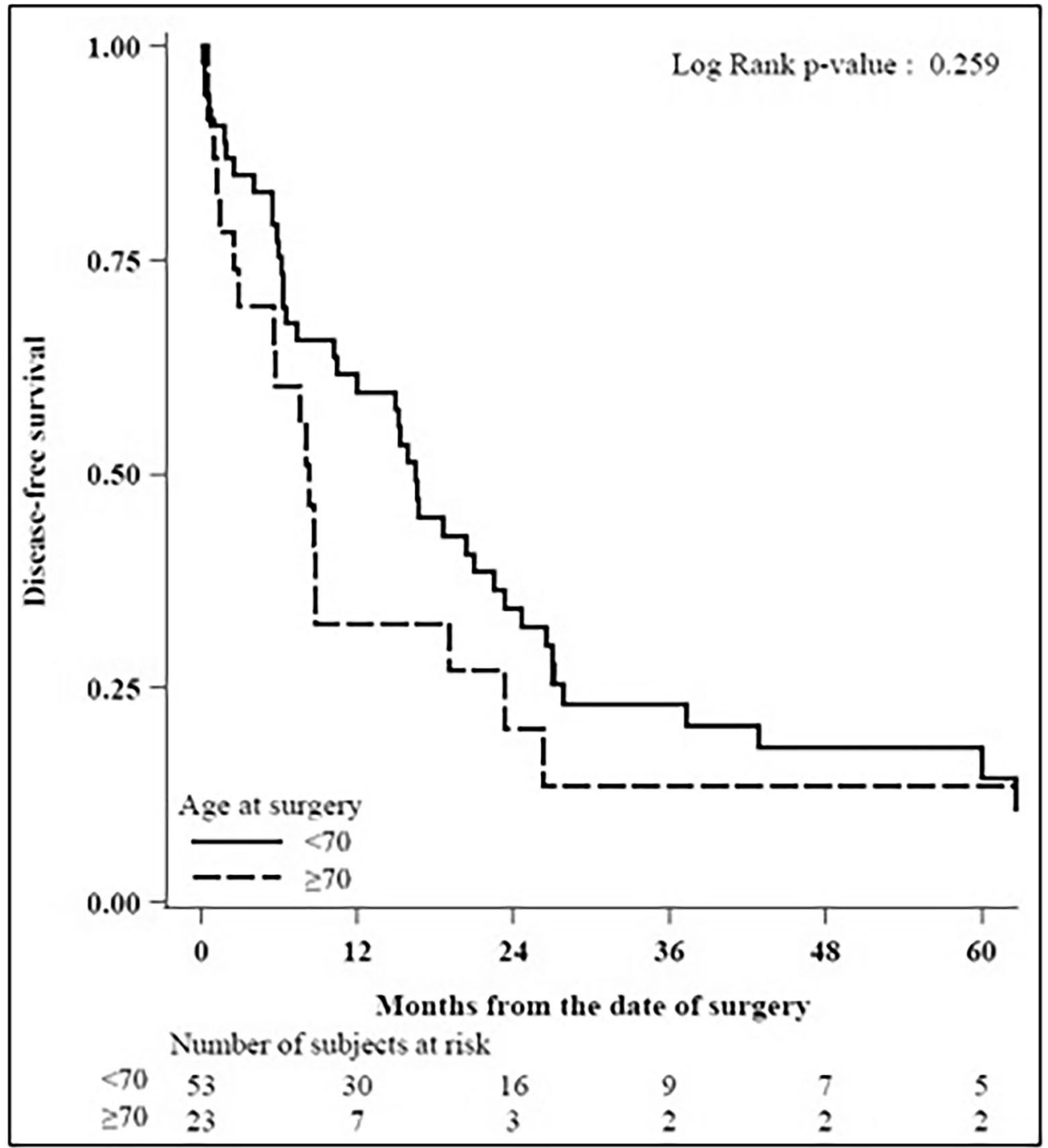

\begin{tabular}{cccccc}
\hline Age at surgery & Events $^{\prime}$ & $\begin{array}{c}\text { 12-mo DFS } \\
(\mathbf{9 5} \% \mathrm{CI})\end{array}$ & $\begin{array}{c}24-\mathrm{mo} \text { DFS } \\
(\mathbf{9 5} \% \mathrm{CI})\end{array}$ & $\begin{array}{c}36-\mathrm{mo} \mathrm{DFS} \\
(\mathbf{9 5} \% \mathrm{CI})\end{array}$ & $\begin{array}{c}\text { 60-mo DFS } \\
(\mathbf{9 5} \% \mathrm{CI})\end{array}$ \\
\hline 70 & $43(81.1 \%)$ & $59.6(45.0-71.5)$ & $34.2(21.4-47.5)$ & $23.2(12.4-35.9)$ & $18.0(8.5-30.5)$ \\
$\geq 70$ & $19(82.6 \%)$ & $32.5(14.6-51.8)$ & $20.3(6.0-40.4)$ & $13.5(2.6-33.5)$ & $13.5(2.6-33.5)$ \\
\hline
\end{tabular}

Fig. 3 Disease-free survival

treatment because only of advanced age. Other elements should be investigated to better identify elderly patients at risk of complications after major hepatic resection. Further studies evaluating a wider number of patients are needed to better define these concurrent risk factors.
Funding Open access funding provided by Università degli Studi di Milano - Bicocca within the CRUI-CARE Agreement. No funding received in the course of study, research, or assembly of the manuscript. 


\section{Declarations}

Conflict of interest All authors have no conflict of interest nor competing interests to declare.

Ethics approval No ethical approval was necessary owing to the retrospective, observational, and anonymous nature of this study.

Consent to participate and for publication All patients signed informed consent that data and follow-up will be collected anonymously and are potentially used for scientific analysis.

Open Access This article is licensed under a Creative Commons Attribution 4.0 International License, which permits use, sharing, adaptation, distribution and reproduction in any medium or format, as long as you give appropriate credit to the original author(s) and the source, provide a link to the Creative Commons licence, and indicate if changes were made. The images or other third party material in this article are included in the article's Creative Commons licence, unless indicated otherwise in a credit line to the material. If material is not included in the article's Creative Commons licence and your intended use is not permitted by statutory regulation or exceeds the permitted use, you will need to obtain permission directly from the copyright holder. To view a copy of this licence, visit http://creativecommons.org/licenses/by/4.0/.

\section{References}

1. Ethun CG, Lopez-Aguiar AG, Anderson DJ, Adams AB, Fields RC, Doyle MB et al (2018) Transplantation versus resection for hilar cholangiocarcinoma: an argument for shifting treatment paradigms for resectable disease. Ann Surg 267(5):797

2. Cillo U, Fondevila C, Donadon M, Gringeri E, Mocchegiani F, Schlitt HJ et al (2019) Surgery for cholangiocarcinoma. Liver Int 39:143-155

3. Frosio F, Mocchegiani F, Conte G, Dalla Bona E, Vecchi A, Nicolini D, Vivarelli M (2019) Neoadjuvant therapy in the treatment of hilar cholangiocarcinoma: review of the literature. World J Gastrointest Surg 11(6):279

4. El-Serag HB, Engels EA, Landgren O et al (2009) Risk of hepatobiliary and pancreatic cancers after hepatitis $\mathrm{C}$ virus infection: a population-based study of U.S. veterans. Hepatology 49:116-123

5. Sharma P, Yadav S (2018) Demographics, tumor characteristics, treatment, and survival of patients with Klatskin tumors. Ann Gastroenterol 31(2):231

6. ISTAT (Istituto nazionale di statistica)

7. World Bank life expectancy from birth-Italy. https://data.worldbank.org/country/Italy
8. Adam R, Frilling A, Elias D et al (2010) Liver resection of colorectal metastases in elderly patients. Br J Surg 97:366-376

9. Oishi K (2014) Safety of hepatectomy for elderly patients with hepatocellular carcinoma. World J Gastroenterol 20:15028

10. Nozawa A, Kubo S, Takemura $S$ et al (2015) Hepatic resection for hepatocellular carcinoma in super-elderly patients aged 80 years and older in the first decade of the 21 st century. Surg Today 45:851-857

11. Bosman FT, Carneiro F, Hruban RH et al (2010) WHO classification of tumors of the digestive system, 4th edn. International Agency for Research on Cancer, Lyon

12. Amin MB, Edge $S$, Greene F et al (2017) AJCC Cancer Staging Manual, 8th edition-Chapter 23: Intrahepatic Bile duc 2017

13. Dindo D, Demartines N, Clavien P-A (2004) Classification of surgical complications. Ann Surg 240:205-213

14. Charlson ME, Pompei P, Ales KL et al (1987) A new method of classifying prognostic comorbidity in longitudinal studies: development and validation. J Chronic Dis 40(5):373-383

15. Tufo A, Dunne DF, Manu N, Lacasia C, Jones L, de Liguori Carino N et al (2019) Changing outlook for colorectal liver metastasis resection in the elderly. Eur J Surg Oncol 45(4):635-643

16. Nachmany I, Pencovich N, Zohar N, Goykhman Y, Lubezky N, Nakache R et al (2016) Resection of colorectal liver metastases in the elderly-is it justified? J Surg Oncol 113(5):485-488

17. Vitale A, Spolverato G, Bagante F, Gani F, Popescu I, Marques $\mathrm{HP}$ et al (2016) A multi-institutional analysis of elderly patients undergoing a liver resection for intrahepatic cholangiocarcinoma. J Surg Oncol 113(4):420-426

18. Famularo S, Di Sandro S, Giani A, Angrisani M, Lauterio A, Romano F et al (2019) The impact of age and aging on hepatocarcinoma surgery: short-and long-term outcomes in a multicentre propensity-matched cohort. Liver Int 39(5):894-904

19. Papis D, Vagliasindi A, Maida P (2020) Hepatobiliary and pancreatic surgery in the elderly: current status. Ann Hepato-biliaryPancreat Surg 24(1):1-5

20. Akashi K, Ebata T, Mizuno T, Yokoyama Y, Igami T, Yamaguchi $\mathrm{J}$ et al (2018) Surgery for perihilar cholangiocarcinoma from a viewpoint of age: is it beneficial to octogenarians in an aging society? Surgery 164(5):1023-1029

21. Limpawattana P, Wirasorn K, Sookprasert A, Sawanyawisuth K, Titapun A, Luvira V et al (2019) Frailty syndrome in biliary tract cancer patients: prevalence and associated factors. Asian Pacific J Cancer Prev APJCP 20(5):1497

Publisher's Note Springer Nature remains neutral with regard to jurisdictional claims in published maps and institutional affiliations. 